\title{
Sosyal Bilgiler Öğretmenlerinin Küresel Konumlandırma Sistemi ve Coğrafi Bilgi Sistemleri Hakkındaki Görüşleri
}

\section{Erhan GÖRMEZ*, Numan ERTAŞ ${ }^{* *}$}

Öz: $\mathrm{Bu}$ araştırmanın amacı, sosyal bilgiler öğretmenlerinin küresel konumlandırma sistemi (GPS) ve coğrafi bilgi sistemleri (CBS) hakkındaki görüşlerini ortaya koymaktır. Araştırma durum çalışması deseninde, nitel bir çalışmadır. Araştırmanın çalışma grubunu Van ilinde 2018-2019 eğitim/öğretim döneminde görev yapan 17 sosyal bilgiler öğretmeni oluşturmaktadır. Araştırmada veri toplama yöntemi olarak görüşme yönteminden yararlanılmıştır. Araştırmada, öğretmenlerle yapılan görüşmeler sonucu elde edilen veriler, betimsel analiz yöntemi kullanılarak çözümlenmiştir. Araştırmada sosyal bilgiler öğretmenlerinin genel olarak CBS (Coğrafi Bilgi Sistemleri) teknolojisi olarak bilinen GPS sistemini bir konumlandırma sistemi olarak veya uydu aracılığıyla yer tespiti yapan bir sistem olarak tanımladıkları; GPS'in çoğunlukla ulaşım sektöründe ve konum belirlemek amacıyla kullanıldığı; akıllı telefon veya tabletlerde yer alan uygulamaları bildikleri ve bu sistemi sadece bulundukları adresi karşı tarafa göndermek amacıyla kullandıkları; WhatsApp üzerinden (ekle işareti tıklanarak) konum göndermeyi bildikleri ve bu sistemin adres bulma, ulaşım ve iletişimde çok kolaylık sağladığı; bilmedikleri bir şehirde adres sorununu telefonlarındaki GPS veya navigasyon gibi cihazlarla çözdükleri; akıllı telefon veya tabletlerine bir uygulama indirdiklerinde "konumun paylaşılsın mı, konumunuza erişilsin mi? sorusuna genellikle güvenlik amaçlı olarak hayır dedikleri sonuçlarına ulaşılmıştır.

Anahtar Kelimeler: Sosyal bilgiler öğretmeni, Küresel konumlandırma, Coğrafi bilgi sistemleri

\footnotetext{
* Doç.Dr., Van Yüzüncü Yıl Üniversitesi Eğitim Fakültesi, ORCID: 0000-0003-0752-802X erhangormez@hotmail.com

**Arş. Gör. Van Yüzüncü Yıl Üniversitesi Eğitim Fakültesi, ORCID: 0000-0002-1342-0915 numanertas@yyu.edu.tr
}

\begin{tabular}{lll}
\hline Gönderim:01.02.2019 Kabul:02.07.2019 $\quad$ Yayın: 30.09.2019
\end{tabular}


The Views of The Social Studies Teacher on Global Positioning System and Geographic Information Systems

Abstract: The aim of this research is to reveal the views of social studies teachers about global positioning system (GPS) and geographic information systems (GIS). The research is a qualitative study in the case study pattern. The study group of this research consists of 17 social studies teacher working in the province of Van during the 2018-2019 academic year. In the study, interview method was used as data collection. The data gathered from the interviews were analyzed by applying descriptional analysis method. In the study, it is concluded that social studies teachers is defined the GPS system, which is known as GIS (Geographic Information Systems) technology, as a positioning system or as a system for locating by satellite; GPS is mostly used in the transportation sector and for location determination; they know what applications are available on smartphones or tablets, and only use this system to send the address to the opposite side; they know how to send locations via WhatsApp (by clicking the add sign) and this system provides much convenience in address finding, transportation and communication; the problem of address in a city they do not know is solved by devices such as GPS or navigation on their phones; when they download an app to their smartphone or tablet, they usually say no for security purposes to the question of "Share your location or access your location?”

Keywords: Social studies teacher, Global positioning, Geographic information systems

\section{Giriş}

Teknolojik gelişmelerin küreselleşme aracılığıyla hayatımızın tüm alanlarına olan etkisi su götürmez bir gerçekliktir. İnsanın yoğun çalışması sonucu oluşan ve günlük hayatın tüm aşamalarında etkili olan teknoloji, insanı etkisi altına alarak onu yönlendiren bir hal almıştır. Küresel teknolojide meydana gelen bu gelişmeler dünyanın en uzak yerleşim noktasını kısa sürede ulaşılabilir, erişilebilir bir duruma getirmiştir. Mekân kavramının izafi olmasının bir nedeni sayılabilecek olan bu erişilebilirlik kolaylığı zaman ve mekân uyumsuzluğunu en aza indirmiş ve coğrafi konum veya konum olgusuna yaklaşımı değiştirmiştir. Genelde teknoloji özelde ise iletişim sistemlerinde ortaya çıkan yenilikler mekân olgusunu veya erişilebilirliğini değiştirdiği gibi dünyadaki bütün insanlar arasında bir ağın ortaya çıkmasını sağlamıştır. İletişim olarak adlandırılan bu ağ ise farklı biçim ve yöntemlerle en ilkel insanlarda olduğu gibi günümüzde de çok yönlü ve çok fonksiyonlu bir şekilde uygulanmaktadır. İşaret, dil, yazı ve sembol gibi birçok yöntemi olan iletişim yöntemleri yerini günümüzdeki kitle 
iletişim araçlarına bırakmıştır. Birçok kitle iletişim aracının (posta, faks, radyo, kablolu telefon vb.) günümüzde neredeyse hiç kullanılmamasının yanında var olan kitle iletişim araçlarında yeni gelişmeler kaydedilmektedir. Bu gelişmeler cep telefonu ve internet başta olmak üzere mevcut kitle iletişim araçlarının kullanım alanlarını ve insan hayatına katkısını önemli ölçüde etkilemektedir.

Zaman ve mekân bütünlüğünü ve uyumunu sağlamada önemli gelişmeler ve kolaylıklar sağlayan internet erişiminin her an ve her yerde ulaşılabilirliği, kitle iletişim araçlarının en önemli gelişmelerinden sayılabilir. Kablosuz telefon (cep telefonu) ve internet gibi kitle iletişim araçlarını veya ağlarını kullanma olanağı sağlayan temel teknoloji ise GPS (Global Positioning System) olarak bilinen Küresel Konumlama Sistemi'dir. Uydu Ağ1, Yer Kontrol Ağ1 ve Alıcılar bölümlerinden oluşan GPS'in karmaşık bir sistem olduğunu belirten Prasad ve Ruggieri (2005) buna rağmen GPS'in yeryüzündeki donanım, yazılım ve yenilikler için sürekli bir teknoloji kullanım kaynağı olduğunu belirtmektedir (s.40).

Bunun yanı sıra GPS ile ilgili çok sayıda tanım ve açıklama yapılmakla birlikte kavramsal olarak değişiklik göstermediğini belirtmek gerekir. GPS'in en yaygın tanımını Turoğlu (2008) şöyle ifade etmektedir:

"Uydular yardımı ile bulunduğu noktanın enlem ve boylamlardan oluşan sayısal değerini veya koordinatlarını veren, diğer bir ifade ile mekânsal özelliklerin sayısal tanımlamalarını, koordinat sistemi içinde son derece hassas olarak yapan bir araçtır (s.18)”.

Yalın bir ifade ile GPS, uzaya yerleştirilmiş uydular ile bu uyduları gören alıcılar yoluyla yeryüzündeki konum, yön, yükseklik, eğim, derinlik, alan ve hız gibi çeşitli özellikleri tespit edebilen bir sistemdir (Tuna, 2015). Konumlandırma, izleme ve haritalama için kullanılan GPS çoğu durumda navigasyon ile eş anlamlı olarak bilinmektedir. Aslında navigasyonun veri kaynağı olan GPS teorik navigasyon kavramını gerçek bir sisteme dönüştüren, yaygın olarak kabul gören, dünya genelinde kullanılan ve gittikçe ihtiyaç duyulan bir sistemdir (Prasad ve Ruggieri, 2005).

GPS sistemi 1960'lı yıllarda Amerika Birleşik Devletleri tarafından ve NASA'nın da desteğiyle Savunma Bakanlığı için geliştirilmiş bütün hava koşullarında konum belirleyebilen veya fonksiyonel olarak çalışabilme özelliğine sahiptir. Konumlandırma, veri oluşturma ve üretme hizmetleri sunan GPS bir Amerikan buluşu olmasının yanında bu alanda hizmet veren tek sistem değildir. Rusya'nın geliştirmiş olduğu GLONASS (Globalnaya Navigatsionnaya Sputnikovaya Sistema), Fransa'nın geliştirmiş olduğu DORIS (Doppler Orbitography ve 
Radio-Positioning Integrated by Satelite), Avrupa Birliğinin 2011 yılından beri üzerinde çalıştığı GALILEO uydu sistemi, Çin'in geliştirdiği BEIDOU ve Japonya'nın geliştirdiği QUASI-ZENITH uydu konumlandırma sistemi bu alanda hizmet veren araçlardan bazılarıdır (Christopher ve Kaplan, 2006). Fakat bunların içinde en yaygın kullanıcı kitlesine sahip olanı NAVSTAR-GPS' (Navigation System Using Time And - Global Navigation Satelite System)'dir.

GPS’nin işlevsel olması için üç ağının olması gerekmektedir. Bunlar; Uydu Segmenti, Yer Kontrol Segmenti ve GPS Kullanıcı Segmenti şeklinde sıralanır.

Uydu Segmenti (The Space Segment): Sinyalleri kullanıcıya (araç navigasyonu, cep telefonu, bilgisayar vb.) ileten GPS uydu takımını içeren segmenttir. GPS’den hizmet alan bir kullanıcının konum belirleyebilmesi için en az 4 uydudan sinyal alması gerekmektedir.

Kontrol Segmenti (The Control Segment): Uzay Segmentinin izlenmesinden ve işletilmesinden sorumlu olan kontrol segmenti küresel konumlama sisteminin beyin işlevini görmektedir. Uyduların yörüngelerinden çıkmamalarını sağlayan bir sistemdir. Bu segment doğrudan uyduyla bağlantılı olup kontrol segmentine bağlılı̆̆ yoktur.

Kullanıcı Segmenti (The User Segment): Konumlandırma, navigasyon ve zamanlama uygulamaları için kullanıcı donanımı ve işleme yazılımı içeren segmenttir. Hem askeri hem sivil kullanıcıları içeren bu segmentte kullanılan teknolojik cihazlar yer almaktadır (Prasad ve Ruggieri, 2005; Taylor ve Blewwit, 2006; Turoğu, 2000).

$\mathrm{Bu}$ üç segmentin dışında Taylor ve Blevitt'e (2006) göre hatalı konumların iyileştirilmesi sivil izleme ağlarının (örneğin CBS) GPS işlemlerinde sayılması gereken dördüncü segmentin olduğunu belirtmektedir.

Şekil 1: GPS Segment Diyagramı (Kaynak: European GNSS Agency (2017)

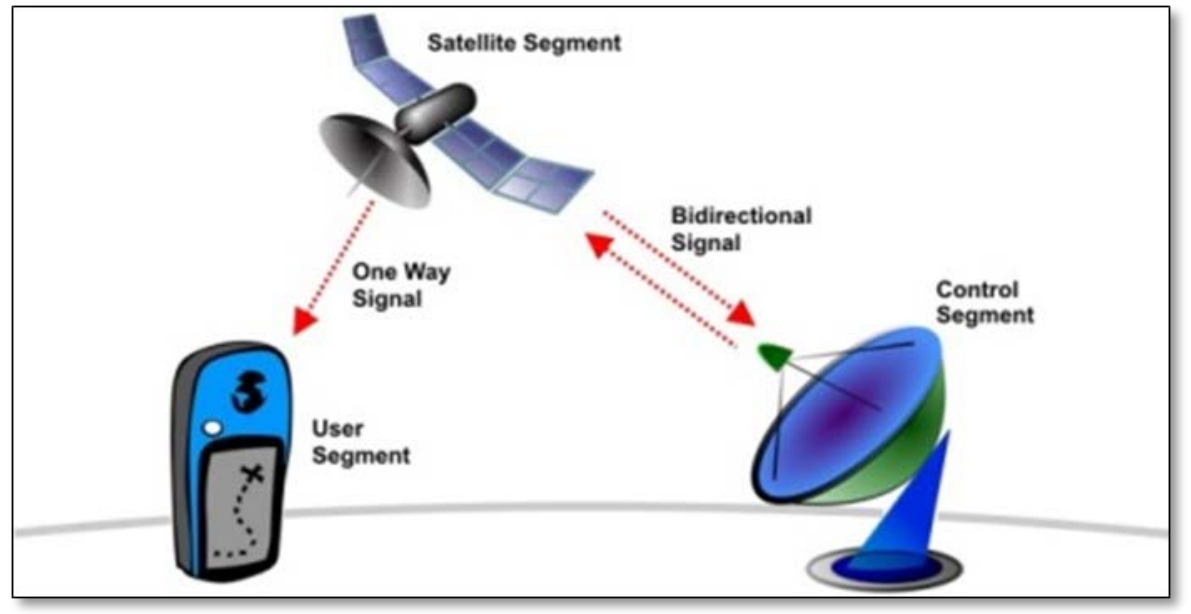


Günümüzde ak1llı telefon, tablet veya bilgisayar kullanan herkes aslında aktif olarak GPS hizmetinden faydalanmaktadır. Fakat çoğunlukla Coğrafi Bilgi Sistemleri (CBS) uygulamalarını kullanarak arka planda çalışan GPS varlığından habersizdir. Askeri amaçların dışında GPS; konum tabanlı bütün hizmetler, karayolu, havacılık, demiryolu, denizcilik, tarım, hayvancılık, haritacılık ile zamanlama ve senkronizasyon alanlarında aktif olarak uygulanmaktadır. Avrupa GNSS Ajansının (European GNSS Agency) 2017 yılında yayınlandığı rapor bazı Lokasyon Temelli (GPS) hizmetlerin öneminden söz etmiştir. Bu hizmetlerin bazıları;

- $\quad$ İşletim Sistemi Geliştiricileri: Apple (IOS), Google (Android), Jolla (Sailfish), Linux Foundation (Linux), Microsoft (Windows), Canonical (Ubuntu),

- $\quad$ Uygulama Mağazaları: (Google Play, Apple App Store, Amazon App Store, 360 Mobile Assistant, Blackberry World, Windows Phonestore vb),

- Mobil Şebeke Operatörleri ve Veri Sağlayıcıları: (Telefonica, Orange, At\&t Mobility, Turkcell, Vodafone vb.),

- $\quad$ Harita Sağlayıcıları: (Google maps, Google earth, Apple Map gibi),

- Uygulama Geliştiriciler: (Facebook, İnstagram, Foursquare, Google, Tripadvisor, Iac Nokia ve daha çok sayıda uygulama geliştirici),

- $\quad$ Bütün akıllı telefon, tablet, bilgisayar ve kameralar,

- $\quad$ Cep, Saat, Araç içi ve El Navigasyon Araçları,

- Havayolu, Demiryolu, Karayolu ve Denizyolu gibi ulaşım ağlarının rota tespiti ve ulaşım güzergâhının belirlenmesi,

- $\quad$ İnsan ve araç takibi gibi faaliyetler için geliştirilen çipler şeklinde sıralanabilir (European GNSS Agency, 2017).

GPS’nin temel, askeri, ticari, profesyonel ve özel kullanıcılara sunduğu hizmetler düşünüldüğünde iletişim ağları başta olmak üzere yapılan bütün teknolojik aktivitelerin aslında GPS'den bağımsız olamayacağını kanıtlamaktadır. Bu kullanım şekillerinin büyük çoğunluğu Coğrafi Bilgi Sistemleri veya haritalama yoluyla kullanılmaktadır. Profesyonel, askeri ve özel kullanıcıların dışında kalan ve temel kullanıcılardan oluşanlar telefon konuşarak, internette gezinerek, haritada yer bakarak, haritada adres bularak veya haritalardan belirtilen konuma ulaşmaya çalışarak GPS hizmetinden faydalanmaktadır. Akıllı telefon veya tablet yoluyla adres (konum - location) paylaşımının olması, telefon veya tablet uygulaması edinirken konum paylaşımının yapılması veya reddedilmesi gibi faaliyetler GPS kullanımı ile ilgilidir. 
Söz konusu sistemlerle yukarıda adı geçen konumsal olan veya olmayan tüm bilgileri kullanarak, coğrafi ve mekânsal analizler üreten alan ise Geographic Information System olarak adlandırılan ve Coğrafi Bilgi Sistemleri olarak bilinen CBS’dir (Tecim, 2008). Küresel Konumlama Sistemi (GPS), Coğrafi Bilgi Sistemleri (CBS) uygulamalarında kullanım kolaylığı sağlamaktadır. Turoğlu (2000) CBS'in veri formatına uygun veri üretmesi, coğrafi konum (location) sayısal verilerine hemen o an ulaşabilme imkânı, sayısal verilerin doğru ve güvenilir olması, her ortam ve hava şartlarında harekete duyarsız bir şekilde veri sağlaması gibi kolaylıkların CBS uygulamalarında kullanımı arttırdığını ifade etmiştir. Nitekim kullanışlı olması, taşınabilir olması, kolay ve pratik olması da önem arz etmektedir.

Bilgisayar teknolojilerinin çok hızlı gelişmesi ile birlikte uygulama alanı bulan GPS ve CBS sistemlerinin kullanıldığı alanlardan biri de eğitim kurumlarıdır. CBS'nin ortaöğretimde kullanılmasına 1980'li yılların sonunda ABD ve İngiltere gibi ülkelerde özellikle coğrafya gibi mekânla ilgili olan derslerin öğretilmesinde başlanmıştır. İngiltere'de CBS'nin ilk olarak Ortaöğretim Coğrafya Öğretim Programına adapte edilmesi 1988 yılında uygulanmaya konulan ulusal öğretim programı ile gerçekleştirilmiştir. Birçok ülke CBS'nin eğitim ve öğretim açısından taşımış olduğu potansiyelin farkına vardığından bu uygulamalar yaygınlık kazanmıştır (Demirci, Karaburun, Ünlü ve Özey, 2013). Bu bağlamda GPS ve CBS gibi teknoloji tabanlı sistemlerini kullanabilecek yeterlilikte öğretmene ihtiyaç da artmış durumdadir.

Çünkü bilgisayar teknolojilerinde meydana gelen değişimleri yakından takip ederek bunu sınıf ortamına taşıyan kişiler öğretmenlerdir. Öğretmenlerin teknolojinin birçok alanında meydana gelen değişim ve yenilikleri yakından takip ederek, bunları öğrencileriyle paylaşmaları, küresel vatandaş yetiştirme amacı güden eğitim sistemlerinin en nihai hedefidir. $\mathrm{Bu}$ genel hedefi gerçekleştirme konusunda önemli görevler üstlenen branşların başında sosyal bilgiler öğretmenleri gelmektedir. En temel amacı etkili ve nitelikli vatandaş yetiştirme olan sosyal bilgiler dersinin uygulayıcıları konumunda olan öğretmenlerin, bilgisayar destekli bilgi teknolojilerini kullanabilmeleri ve bu beceriyi etkili kullanma konusunda öğrencilerine rol model olmaları, sosyal bilgiler öğretim programının hedeflerine ulaşması bakımından oldukça önemlidir. 


\section{Araştırmanın Amacı}

$\mathrm{Bu}$ çalışmada amaçlanan sosyal bilgiler öğretmenlerinin GPS ve CBS sistemleri hakkında ne düşündüklerini ortaya koymaktır. $\mathrm{Bu}$ amaç doğrultusunda aşağıdaki alt problemlere cevap aranmıştır.

1. Sosyal bilgiler öğretmenlerinin CBS (Coğrafi Bilgi Sistemleri) teknolojisi olarak bilinen GPS sistemi ile ilgili görüşleri nelerdir?

2. Sosyal bilgiler öğretmenlerinin GPS'in kullanım alanları ve ne işe yaradığı ile ilgili görüşleri nelerdir?

3. Sosyal bilgiler öğretmenlerinin akıllı telefon veya tabletlerde yer alan konum veya konumlandırma hizmetleri ile ilgili görüşleri nelerdir?

4. Sosyal bilgiler öğretmenlerinin bir mesajlaşma ve arama uygulaması olan WhatsApp'tan birine konum gönderme ile ilgili düşünceleri nelerdir?

5. Sosyal bilgiler öğretmenlerinin bilmedikleri bir şehirde adres bulma sorununu nasıl çözdükleri ile ilgili görüşleri nelerdir?

6. Sosyal bilgiler öğretmenlerinin akıllı telefon veya tabletlerine bir uygulama indirdiklerinde "konumunun paylaşılsın mı, konumunuza erişilsin mi?" sorularıyla ilgili görüşleri neleridir?

\section{Yöntem}

Araştırma, nitel bir çalı̧̧ma olup, durum çalışması desenindedir. Durum çalışması deseni farklı sosyal olguları betimlemek, açıklamak ve değerlendirmek amacıyla kullanılmaktadır. Durum çalışmaları gerçekte ortamda neler olduğuna bakma, sistematik bir biçimde verileri toplama, analiz etme ve sonuçları ortaya koyma yoludur (Aytaçlı, 2012). Bu araştırma Milli Eğitim Bakanlığına bağlı Van ilinde bulunan 9 ortaokulda görev yapan toplam 17 sosyal bilgiler öğretmenin GPS ve CBS sistemleri hakkında ne düşündüklerini değerlendirmeyi amaçlamaktadır.

Durum çalışması sekiz aşamadan oluşmaktadır (Yıldırım ve Şimşek, 2011). Durum çalışması deseninde hazırlanan bu çalışmada takip edilen 8 aşama incelendiğinde:

1. Araştırma Sorularının Geliştirilmesi: Araştırmanın konusu dikkate alınarak öğretmenlerin GPS ve CBS sistemleri hakkında ne düşündüklerini ortaya koyan sorular hazırlanmıştır. Soruların hazırlanmasında alan yazında yapılan çalışmalar, Sosyal Bilgiler Öğretim Programı, CBS konusunda uzman bir akademisyen ile Sosyal Bilgiler Öğretiminde uzman bir akademisyenin görüşleri incelenerek görüşme soruları hazırlanmıştır. 
2. Araştırmanın Alt Problemlerinin Geliştirilmesi: Araştırmanın ana problemi olan "sosyal bilgiler öğretmenlerinin küresel konumlandırma sistemi (GPS) ve coğrafi bilgi sistemleri (CBS) hakkındaki görüşleri nelerdir?” Sorusunu daha anlaşılır kılmak ve probleme ilişkin ayrıntılı yanıtlar bulunmak için araştırmanın ana problemi 6 alt probleme bölünmüştür.

3. Analiz Biriminin Saptanmas1: Sosyal bilgiler öğretmenlerinin CBS ve GPS hakkındaki bilgileri analiz birimi olarak saptanmıştır.

4. Çalış1lacak Durumun Belirlenmesi: Sosyal bilgiler öğretmenlerinin CBS ve GPS hakkında ne düşündükleri çalışılacak durum olarak belirlenmiştir.

5. Araştırmaya Katılacak Bireylerin Seçimi: Araştırmanın problemi doğrultusunda çalışma grubu belirlenmiştir. Çalışma grubu, nitel araştırma geleneği içinde ortaya çıkan örneklem tekniklerinden biri olan amaçlı (kasti) örnekleme tekniğine göre belirlenmiştir. $\mathrm{Bu}$ teknik için de birçok örneklem çeşidi yer almaktadır. Çalışma grubunda yer alan öğretmenler kolay ulaşılabilir örneklem türüne göre belirlenmiştir.

6. Verinin Toplanması ve Toplanan Verinin Alt Problemlerle İlişkilendirilmesi: Araştırmada veri toplama yöntemi olarak yapılandırılmış görüşme yöntemi kullanılmıştır. Görüşme soruları, çalışmanın problemini derinleştirmek amacıyla hazırlanmış olan 6 alt problemle ilişkilendirilmeye çalışılmıştır.

7. Verinin Analiz Edilmesi ve Yorumlanması: Sosyal bilgiler öğretmenleri ile yapılan görüşmelerinden elde edilen veriler, betimsel analiz yöntemi kullanılarak çözümlenmiştir. Bulguları somutlaştırmak amacıyla da ulaşılan veriler tablolaştırılarak yorumlanmıştır.

8. Durum Çalışmasının Raporlaştırılması: Durum çalışmasında elde edilen veri seti sadeleştirilmeye çalışılmıştır. Elde edilen verilerin analizinde ve sunumunda problem ve alt problemlerden yararlanılmıştır. Sonuçların sunumunda ise tablo ve grafiklere yer verilerek karmaşık veriler anlaşı1ır kılınmaya çalışılımıştır.

\section{Çalışma Grubu}

Araştırmanın çalışma grubunu Van ili ve ilçelerinde 2018-2019 eğitim/öğretim döneminde görev yapan 17 sosyal bilgiler öğretmeni oluşturmaktadır.

Tablo 1. Çalışma Grubunda Yer Alan Okullar ve Öğretmen Sayıları

\begin{tabular}{|c|c|c|c|}
\hline \multirow[b]{2}{*}{ Okul Kodları } & \multirow{2}{*}{$\begin{array}{l}\text { Okulun Bulunduğu } \\
\text { İl ve İlçe }\end{array}$} & \multicolumn{2}{|c|}{ Cinsiyet } \\
\hline & & $\begin{array}{c}\text { Erkek } \\
\text { Öğretmen }\end{array}$ & Bayan Öğretmen \\
\hline A ortaokulu & $\begin{array}{c}\text { Van İli/Edremit } \\
\text { İlçesi }\end{array}$ & 2sbö-e & 1sbö-k \\
\hline B ortaokulu & $\begin{array}{c}\text { Van İli/ İpekyolu } \\
\text { İlçesi }\end{array}$ & 1sbö-e & 2sbö-k \\
\hline C ortaokulu & $\begin{array}{c}\text { Van İli/ İpekyolu } \\
\text { İlçesi }\end{array}$ & 1sbö-e & 1sbö-k \\
\hline
\end{tabular}




\begin{tabular}{cccc}
\hline D ortaokulu & $\begin{array}{c}\text { Van İli/ İpekyolu } \\
\text { İlçesi }\end{array}$ & 1 sbö-e & - \\
E ortaokulu & $\begin{array}{c}\text { Van İli/ İpekyolu } \\
\text { İçesi }\end{array}$ & 1 sbö-e & 1 sbö-k \\
F ortaokulu & $\begin{array}{c}\text { Van İli/ İpekyolu } \\
\text { İlçesi }\end{array}$ & 2 sbö-e & 1 sbö-k \\
G ortaokulu & $\begin{array}{c}\text { Van İli/ İpekyolu } \\
\text { İlçesi }\end{array}$ & 1 sbö-e & 1 sbö-k \\
$\begin{array}{c}\text { H ortaokulu } \\
\text { Toplam }\end{array}$ & Van İli/ Tuşba İlçesi & $\begin{array}{c}\text { 1sbö-e } \\
\text { 10sbö-e }\end{array}$ & 7sbö-k \\
\hline
\end{tabular}

Görüşleri alınan öğretmenler görev yaptıkları okullara ve cinsiyetlerine göre kodlanarak tabloda belirtilmiştir. Bayanlar öğretmenler için $\mathrm{K}$, erkekler öğretmenler için de $\mathrm{E}$ harfi kod olarak kullanılırken okullar da A ortaokulu, B ortaokulu, şeklinde alfabetik sıra dikkate alınarak kodlanmıştır. Doğrudan alıntılarda kullanılan SBÖ ifadesi de "sosyal bilgiler öğretmeni” anlamına gelmektedir.

\section{Veri Toplama Yöntemi}

Çalışmada veri toplama yöntemi olarak, yapılandırılmış görüşme yöntemi kullanılmıştır. Bu görüşme, daha çok, önceden yapılan ve ne tür soruların ne şekilde sorulup hangi verilerin toplanacağını en ayrıntılı biçimde saptayan, görüşme planının aynen uygulandığı bir görüşmedir. Bu türde yanıtlayıcıdan önceden belirlenmiş bir dizi soruyu yanıtlaması istenir (Yıldırım ve Şimşek, 2011). Soruların hazırlanmasında konuyla ilgili olarak alan yazında yapılan çalışmalar, Sosyal Bilgiler Öğretim Programı, CBS konusunda uzman bir akademisyen ile Sosyal Bilgiler Öğretiminde uzman bir akademisyenin görüşleri dikkate alınmıştır. Öğretmenlerle görüşme yapmadan önce, görüşme soruları dil ve yeterlilik açısından 1 Türkçe alan uzmanına incelettirilmiştir. Uygulamaya hazır hale getirilen sorular sosyal bilgiler öğretmenlerine uygulanmıştır.

\section{İçerik Analizi}

Araştırmada veriler "Standartlaştırılmış Açık Uçlu Görüşme Formu" aracılığ1 toplanarak, betimsel analiz yöntemi ile çözümlenmiştir Betimsel analiz, elde edilen verilerin önceden belirlenen temalara göre özetlenip yorumlanması yaklaşımıdır. Betimsel analizle, elde edilen veriler, düzenlenerek yorumlanır ve anlaşılır bir biçimde betimlenerek okuyucuya sunulur. Bu betimlemeler yorumlanır, neden-sonuç bağları sorgulanır ve bir takım sonuçlara ulaşılır. Betimsel analizde veriler, sık sık doğrudan alıntılar verilerek yorumlanmaya çalışılır (Yıldırım ve Şimşek, 2011, s.224). 


\section{Çalışma İle İlgili Geçerlik ve Güvenirlik Çalışmaları}

Geçerlik ve Güvenirlik kavramları bilimsel araştırmalarda sonuçların inandırıcılığı için kullanılan en önemli ölçütlerdir. Bu iki ölçüt nitel ve nicel araştırmalarda farklı bir biçimlerde ele alınmaktadır (Yıldırım ve Şimşek, 2011). Yapılan çalışma, nitel araştırma modelinde olduğu için geçerliği ve güvenirliği artırıcı çalışmalar da bu bağlamda ele alınmıştır.

Araştırmada veri toplama aracı olarak görüşme tekniği kullanılmıştır. Bu tekniğin güçlü yanları olan araştırmacının esnek olması, yanlış anlaşıılma durumunda soruyu tekrar etme veya soruyu değişik biçimde tekrarlama, araştırma alanına olan yakınlık, yüz yüze görüşmeler yoluyla ayrıntılı ve derinlemesine bilgi toplama, uzun süreli bilgi toplama, toplanan verilerin ayrıntılı olarak rapor edilmesi ve araştırmacının toplanan verilere nasıl ulaştığını açıklaması gibi durumlarla araştırmanın geçerliliği sağlanmaya çalışılmıştır. Bu çalışmada da araştırmacı araştırma alanında doğrudan bulunarak hazırlamış olduğu görüşme formu aracılığıyla öğretmenlerin görüşlerini almaya çalışmış, araştırma alanında bizzat kendisi bulunmuş, anlaşılmayan soruları açıklamaya çalışmış, toplanan bilgiler ayrıntılı biçimde raporlanmaya çalışılmıştır. Çalışmada araştırmanın güvenirliğini artırmak için de araştırmacı öğretmenlere görüşme formunu vermeden önce kendi konumu ve yapacağı çalışma hakkında bilgi vermeye çalışmış, adayların sorulara detaylı ve içtenlikle cevap vermeleri istenmiş, araştırmada veri kaynağı olan öğretmenler ile ilgili bilgiler makalede çalışma grubu başlığı altında açık biçimde tanımlanmış, veri analizinde kullanılan betimsel analiz yöntemi ile alakalı kavramların çerçevesi detaylı biçimde açıklanmış, öğretmenlerden elde edilen veriler bulgular kısmında herhangi bir yorum katmadan okuyucuya sunulmaya çalışılmıştır.

\section{Bulgular}

Bulgular bölümünde veri toplama aracı ile elde edilen veriler tablolar ile gösterilerek analiz edilmeye çalışılmıştır. Ayrıca ulaşılan bulguları destekleyen öğretmen görüşlerinden doğrudan alıntılara da yer verilmiştir.

Tablo 2. Sosyal Bilgiler Öğretmenlerinin CBS (Coğrafi Bilgi Sistemleri) Teknolojisi Olarak Bilinen GPS Sistemi ile İlgili Görüşleri

\begin{tabular}{cc}
\hline Öğretmen görüssleri & f \\
\hline Mobil telefonlar, tabletler, bilgisayar, araba ve diğer & $1 \mathrm{e}$ \\
araçlarda kullanılan yer tespit sistemi & - \\
Uydu aracılı̆̆ylla yer tespiti yapan bir sistem & $4 \mathrm{e}$ \\
& $2 \mathrm{k}$ \\
Konumlandırma sistemi & $3 \mathrm{e}$ \\
& $3 \mathrm{k}$ \\
Adres yada uzak yerlerin incelenmesi & - \\
Yeryüzündeki bir alanın sınırlarının ve içeriğinin & $1 \mathrm{k}$ \\
çizimi & $1 \mathrm{e}$ \\
\hline
\end{tabular}


Tablo 2 incelendiğinde Sosyal Bilgiler Öğretmenlerinin GPS sistemini "Uydu aracılığıyla yer tespiti yapan bir sistem; Konumlandırma sistemi” olarak tanımladıkları görülmektedir. Genel olarak hem bayan hem de erkek öğretmenlerin GPS sistemini birbirine yakın ifadelerle tanımladıkları da görülmektedir.

Birinci bulguyla ilgili öğretmenlerin görüşlerini yansıtan doğrudan aktarılmış ifadeler incelendiğinde:

SBÖE-D Okulu: Mobil telefonlar, tabletler, bilgisayarlar, arabalar ve diğer araçlarda kullanılan yer tespit sistemi olarak biliyorum. Mühendislik, hava ve deniz yolları gibi alanlarda daha çok kullanilır. Uydu aracıllğ̆ıyla yer tespiti yapan bir sistemdir.

SBÖK-E Okulu: Konuya çok hakim olmamakla beraber bir alanın sinırlarının grafik ve haritalarla gösterilmesidir. Teknolojik boyutu olan bir uygulamadır.

SBÖK-B Okulu: Uydudan haritalara yanslyan görsel bilgilerdir. Bu bilgiler günceldir ve kolaylık să̆lar.

Tablo 3. Sosyal Bilgiler Öğretmenlerinin GPS'in Kullanım Alanları Ne İşe Yaradığı veya Nasıl Kullanıldığı ile İlgili Görüşleri

\begin{tabular}{cc}
\hline Öğretmen görüşleri & f \\
\hline Ulaşım & $3 \mathrm{e}$ \\
Mühendislik alanları & $3 \mathrm{k}$ \\
Askeri alanlar & $1 \mathrm{e}$ \\
Trafikte & - \\
Turizm & - \\
& $1 \mathrm{e}$ \\
Tarım & $1 \mathrm{k}$ \\
Spor & $1 \mathrm{e}$ \\
& - \\
Ormancılık & $1 \mathrm{e}$ \\
& - \\
Konum belirleme & $1 \mathrm{e}$ \\
İletişim & - \\
Sosyal hayat & $1 \mathrm{e}$ \\
Şehir planlamada & - \\
& $5 \mathrm{e}$ \\
İtfaiye, polis, ambulans, finans sektörü & $5 \mathrm{k}$ \\
& $1 \mathrm{e}$ \\
Denetimli serbestlik mahkûmlarda & - \\
& $-1 \mathrm{e}$ \\
& - \\
& $2 \mathrm{k}$ \\
& - \\
& $1 \mathrm{k}$ \\
& - \\
& $1 \mathrm{k}$ \\
\hline
\end{tabular}


Tablo 3 incelendiğinde Sosyal Bilgiler Öğretmenleri GPS'nin konum belirlemek ve ulaşım amaçlı kullanıldıklarını ifade etmişleridir. Erkek öğretmenlerin GPS’nin kullanım alanları açısından daha çeşitli bilgilere sahip olduğu görülmektedir.

İkinci bulguyla ilgili öğretmenlerin görüşlerini yansıtan doğrudan aktarılmış ifadeler incelendiğinde:

SBÖE-D Okulu: Ulaşım, mühendislik alanları, askeri alanlarda, trafikte

SBÖK-E Okulu: Şehir planlamalarında detayl yansıtmalar için kullanılmaktadır.

SBÖK-B Okulu: Yön, şehir planlama, parsel sorgulama, itfaiye, polis, ambulans, belediye çöp toplama noktaları, finans sektörü bilgileri, adres, konum vb. kullanım alanları vardır.

Tablo 4. Sosyal Bilgiler Öğretmenlerinin Akıllı telefon veya tabletlerde yer alan konum veya konumlandırma hizmetleri ile ilgili görüşleri

\begin{tabular}{cc}
\hline Öğretmen görüşleri & f \\
\hline İnternet bağlantılı cihazlarda harita programını & $3 \mathrm{e}$ \\
açtı̆̆ımızda yerimizi gösterir. & $1 \mathrm{k}$ \\
Karşı tarafın bizi daha kolay bulması için konum & $2 \mathrm{e}$ \\
göndeririz & - \\
Biliyorum, bulunduğumuz yerin adresini karşı tarafa & $2 \mathrm{e}$ \\
gönderebilmemiz için kolaylık sağlar & $5 \mathrm{k}$ \\
Bilmiyorum & $2 \mathrm{e}$ \\
& $1 \mathrm{k}$ \\
İlk kez gezip göreceğim yerlerde kullanıyorum & - \\
& $1 \mathrm{k}$ \\
\hline
\end{tabular}

Tablo 4 incelendiğinde Sosyal Bilgiler Öğretmenleri “Akıllı telefon veya tabletlerde yer alan konum veya konumlandırma hizmetlerini biliyor musunuz?" sorusuna genel olarak "Biliyorum, bulunduğumuz yerin adresini karşı tarafa gönderebilmemiz için kolaylık sağlar" şeklinde cevap verdiği görülmektedir.

Üçüncü bulguyla ilgili öğretmenlerin görüşlerini yansıtan doğrudan aktarılmış ifadeler incelendiğinde:

SBÖE-D Okulu: İnternetin olduğu cihazlarda (bazı programlar internet olmadan da çalışabiliyor) kullanılan cihazlarda harita programını açtığımızda bulunduğumuz yeri otomatik olarak gösteriyor. Güncel olmayan programlar yada cihazlarda bu bilgiler doğru olmayabilir.

SBÖK-E Okulu: Evet, teknolojiden yararlanarak bulunduğumuz yeri ifade etme ve yol tariflerinde kullandiğımız bir hizmet

SBÖK-B Okulu: Biliyorum. Kendi konumumu beni ziyaret etmek isteyen, misafir olarak gelmek isteyen yada benimle görüşmek isteyenlere paylaşırım. Görüşmek istediğim yada adresini öğrenmek istediğim kişilerden konum isterim. 
Tablo 5. Sosyal Bilgiler Öğretmenlerinin WhatsApp Uygulaması ile İlgili Görüşleri

\begin{tabular}{cc}
\hline Öğretmen görüssleri & f \\
\hline Biliyorum, Ulaşım ve iletişimi kolaylaştırıyor & $3 \mathrm{e}$ \\
Evet, sohbet ekranından ataç simgesi tıklanarak & $3 \mathrm{k}$ \\
Biliyorum, adres bulmada kolaylık sağlıyor & $1 \mathrm{e}$ \\
& - \\
Bilmiyorum & $3 \mathrm{e}$ \\
& $4 \mathrm{k}$ \\
& $2 \mathrm{e}$ \\
\hline
\end{tabular}

Tablo 5 incelendiğinde Sosyal Bilgiler Öğretmenlerinin genel olarak WhatsApp'tan birine konum göndermeyi bildikleri ve bu uygulamanın da "Ulaşım ve iletişimi kolaylaştırdığını ve adres bulmada kolaylık sağladığını” ifade ettikleri görülmektedir.

Dördüncü bulguyla ilgili öğretmenlerin görüşlerini yansıtan doğrudan aktarılmış ifadeler incelendiğinde:

SBÖE-D Okulu: Biliyorum, ulaşımı ve iletişsimi kolaylaştırması açısından son derece önemli görüyorum.

SBÖE-H Okulu: Evet konumumuzu göndermek için göndermek istediğimiz kişinin sohbet ekranını açıp ve să̆ üstteki ataş simgesine dokunduktan sonra açılan kutudan konum simgesine dokunarak konum gönderilir.

SBÖK-E Okulu: İnsan hayatını oldukça kolaylaştıran bir uygulama olmakla beraber gideceğimiz noktayı en doğru şekilde göstermesinden dolayı zaman açısından tasarruf sağalar. SBÖK-B Okulu: Biliyorum. Adres bulma konusunda çok kolaylık sağllyor. Çok iyi bir uygulama olduğunu düşünüyorum.

Tablo 6. Sosyal Bilgiler Öğretmenlerinin Bilmedikleri Bir Şehirde Adres Sorununu Nasıl Çözdükleri ile İlgili Görüşleri

\begin{tabular}{cc}
\hline Öğretmen görüsşleri & f \\
\hline Telefonumdaki GPS’den yararlanıyorum & $3 \mathrm{e}$ \\
Yakın bir yerse taksi duraklarına veya büfelere & $5 \mathrm{k}$ \\
sorarım & $1 \mathrm{e}$ \\
Akıllı telefon yada navigasyon yoluyla & - \\
Sorarak bulmaya çalışırım & $4 \mathrm{e}$ \\
Telefonumdan konum göndererek bulmaya & $1 \mathrm{k}$ \\
çalışıorum & $3 \mathrm{e}$ \\
Google maps ile buluyorum & - \\
Whatsapp’tan konum bilgilerini açarak & - \\
& $2 \mathrm{e}$ \\
\hline
\end{tabular}


Tablo 6 incelendiğinde Sosyal Bilgiler Öğretmenlerinin bilmedikleri bir şehirde adres bulma sorununu genel olarak "Telefondaki GPS'den yararlanarak; ak1llı telefon veya navigasyon yoluyla çözerim" şeklinde cevap verdikleri görülmektedir. Ayrıca tabloda erkek öğretmenlerin bir kısmının adresleri "sorarak bulmaya çalıştıkları da" görülmektedir.

Beşinci bulguyla ilgili öğretmenlerin görüşlerini yansıtan doğrudan aktarılmış ifadeler incelendiğinde:

SBÖE- D Okulu: Öncelikle telefonumdaki GPS'ten faydalanıyorum. Yakına ulaştı̆̆ımda ise genelde taksi duraklarl veya büfelerden soruyorum.

SBÖK-E Okulu: Telefondaki konum bulma uygulamalarından faydalanırım.

SBÖK-B Okulu: Whatsapp’tan konum bilgilerimi açarak.

Tablo 7. Sosyal Bilgiler Öğretmenlerinin Akı1lı Telefon Veya Tabletlerine İndirdikleri Uygulamalarla ilgili Görüşleri

\begin{tabular}{cc}
\hline Öğretmen görüşleri & f \\
\hline Beni arayan birinin yerimi bilmesi için istemeyerek & $3 \mathrm{e}$ \\
de olsa kabul ediyorum. & $2 \mathrm{k}$ \\
Zararlı tarafları var & $1 \mathrm{e}$ \\
Güvenlik açısından izin vermem & - \\
İzin ver butonuna tıklarım & $5 \mathrm{e}$ \\
Hiç uygulama indirmedim & $5 \mathrm{k}$ \\
& - \\
\end{tabular}

Tablo 7 incelendiğinde "Akıllı telefon veya tabletinize bir uygulama indirdiğinizde "konumunun paylaşılsın mı, konumunuza erişilsin mi?" sorusuna genel olarak "Güvenlik açısından izin vermem; Beni arayan birinin yerimi bilmesi için istemeyerek de olsa kabul ediyorum" şeklinde cevap verdikleri görülmektedir.

Altıncı bulguyla ilgili öğretmenlerin görüşlerini yansıtan doğrudan aktarılmış ifadeler incelendiğinde:

SBÖE-D Okulu: İstemeyerek de olsa kabul ediyorum. Çünkü beni arayan bir yakınım yerimi bilmesi gerektiğinde bu uygulamadan faydalanmasını sağllyor. Tabi ki de zararlı tarafları da var.

SBÖE-H Okulu: Bu gibi durumlarda güvenlik açısından dolayı izin vermem SBÖK-E Okulu: izin ver butonuna tıklarım ve telefonum oranın konum bulmasını sağlar. 
SBÖK-B Okulu: Bulunduğum yeri bildiriyorum. İşime yartyor ise paylaşlyorum, değilse izin vermiyorum.

\section{Tartışma ve Sonuç}

$\mathrm{Bu}$ araştırmanın amacı sosyal bilgiler öğretmenlerinin küresel konumlandırma sistemi (GPS) ve coğrafi bilgi sistemleri (CBS) hakkındaki görüşlerini ortaya koymaktır. Bu amaç doğrultusunda sosyal bilgiler öğretmenleri ile yapılan görüşme sonucu elde edilen ilk bulgu incelendiğinde; öğretmenlerin genel olarak CBS (Coğrafi Bilgi Sistemleri) teknolojisi olarak bilinen GPS sistemini bir konumlandırma sistemi olarak veya uydu aracılığıyla yer tespiti yapan bir sistem olarak tanımladıkları görülmektedir. Sosyal bilgiler öğretmenlerin yapmış oldukları tanımların yeterince açıklayıcı olmadığı, konuyu genel bir biçimde açıkladıkları görülmektedir. Alanyazın incelendiğinde özellikle Coğrafya öğretmenleri dışında diğer branş öğretmenlerinin Coğrafi Bilgi Sistemleri (CBS) veya Küresel Konumlandırma Sistemleri (GPS) hakkında ne bildiklerine veya kullanım yeterliliklerine yönelik herhangi bir çalışmanın yapılmadığı görülmektedir. Milson, Kerski ve Demirci (2012) dünyanın birçok bölgesinde, Tayvan'dan Malta'ya, Güney Afrika Cumhuriyeti'nden Şili’ye kadar, coğrafi bilgi sistemlerinin öğretmen ve öğrenciler tarafından öğretici bir materyal olarak kullanıldığını ve bunun da öğretimin kalitesini artırdığını ifade etmiştir. Ülkemizde ise CBS kullanımı 10 yıllık bir geçmişe sahiptir. Ancak farklı ülkelerle kıyas yapıldığında rahatlıkla görülebileceği üzere bu kullanım ülke içindeki tüm coğrafya öğretmenleri dikkate alındığında istenilen seviyede değildir (Demirci, Karaburun, Ünlü ve Özey, 2013). Bu durumun ortaya çıkmasında şüphesiz ki; okul ve eğitim sisteminden, öğretmenlerden, altyapıdan ve öğretim programlarından kaynaklanan farklı faktörler etkili olmaktadır (Demirci 2008). Ancak, öğretmenlerin derslerinde CBS'den farklı yöntemlerle nasıl yararlanabileceğini gösteren yeterli örnek çalışmaların olmaması da bu resmin oluşmasında etkili olmaktadır. Öğretmenlere yönelik olarak günümüze kadar organize edilen eğitim faaliyetlerinde ağırlıklı olarak CBS'nin teknik yönüne vurgu yapılmakta pedagojik açıdan bu teknolojiden öğretimde nasıl yararlanılabileceğini gösteren çalışmalar ise yetersiz kalmaktadır (Akt, Demirci ve diğ, 2013). Artvinli (2009) “Coğrafya öğretmenlerinin coğrafi bilgi sistemleri (CBS)’ne ilişkin yaklaşımları" konulu çalışmasında coğrafya öğretmenlerine yönelik standart bir CBS eğitiminin olmadığı ve MEB ya da üniversiteler tarafindan CBS öğretmen eğitimine ihtiyaç duyulduğu sonuçlarına ulaşmıştır. Ulaşılan ikinci bulgu incelendiğinde öğretmenlerin GPS'in çoğunlukla ulaşım sektöründe ve konum belirlemek amacıyla kullanıldığını ifade ettikleri 
görülmektedir. Öğretmenlerin verdiği cevaplardan birçok farklı kullanım fonksiyonuna sahip CBS sisteminin kullanım amacıyla ilgili yeterli bilgiye sahip olmadıkları görülmektedir. Ulaşılan üçüncü bulgu incelendiğinde öğretmenlerin akıllı telefon veya tabletlerde yer alan uygulamaları bildikleri ve bu sistemi sadece bulundukları adresi karşı tarafa göndermek amacıyla kullandıklarını ifade ettikleri görülmektedir. Öğretmenlerin verdikleri cevaplardan kişinin bulunduğu yerin koordinatlarını öğrenme, harita üzerinde bulunduğu yeri görme, yol tarifi alma, bulunduğu konumu paylaşma, en yakın hastane, eczane, okul, petrol istasyonu vb. yerleri gösterme gibi birçok kullanım alanına sahip konumlandırma hizmetleri hakkında aslında çok da yeterli bir bilgiye sahip olmadıkları anlaşılmaktadır. Ulaşılan dördüncü bulgu incelendiğinde öğretmenlerin WhatsApp üzerinden (ekle işareti tıklanarak) konum göndermeyi bildikleri ve bu sistemin adres bulma, ulaşım ve iletişimde çok kolaylık sağladığı sonuçlarına ulaşılabilir. Öğretmenlerin WhatsApp uygulamasını etkili kullandıklarından dolayı bu uygulamaya ait, konum gönderme de dahil birçok özelliği bildikleri anlaşılmaktadır. WhatsApp uygulamasının hem toplum yaşantısında hem de okul ortamlarında öğretmenler tarafından etkili kullanıldığı bu sonucu destekler niteliktedir. Balcı ve Şahin (2018) WhatsApp'ın internet paketi üzerinden ücretsiz olarak kullanıcılarına sunduğu, sınırsız mesaj, fotoğraf-video ve ses kaydı paylaşımı, okundu görüldü bilgisi verme ve tüm bu özellikleri kurulan grup üzerinden topluca hedef kitleye ulaştırabilme gibi birçok özelliğinden dolayı tüm dünyada en çok kullanılan mesajlaşma uygulaması olduğunu ifade etmişlerdir. Ayrıca WhatsApp uygulamasının son yıllarda günlük iletişim ihtiyacı dışında öğrenme ortamlarında eğitimciler ve diğer paydaşlar tarafından da çok etkili kullanıldığını ortaya koyan araştırmalara da vurgu yapılmıştır. Ulaşılan beşinci bulgu incelendiğinde sosyal bilgiler öğretmenlerinin bilmedikleri bir şehirde adres sorununu telefonlarındaki GPS veya navigasyon gibi cihazlarla çözdüklerini ifade etmişlerdir. En son bulgu da ise öğretmenlerinin akıllı telefon veya tabletlerine bir uygulama indirdiklerinde "konumunun paylaşılsın mı, konumunuza erişilsin mi? sorusuna genellikle güvenlik amaçlı olarak hayır dedikleri sonucuna ulaşılmıştır.

Akıllı telefonlar ile yapılan işlemler telefonun kendi özelliği olduğu gibi bazı işlemleri yapabilmek için çeşitli uygulamaların indirilmesi gerekmektedir. Akıllı telefon uygulamaları indirildiğinde, indirilen bu uygulamaları tam anlamıyla kullanabilmek için takvim izni, rehber izni, konum bilgisi izni, telefon izni, mikrofon izni, mesaj izni, depolama/kayıt ayarları izni ve galeri izni gibi izinler vermek gerekmektedir. Bu uygulama izinleri ile kişisel bilgilerin üçüncü kişilerin eline geçme ihtimalinden dolayı özel yaşamın gizliliğini ve mahremiyeti ile tehlikeler ortaya çıkmaktadır. Karlı, Doğru ve Doğru’nun (2018) 218 üniversite öğrencisine yönelik 
yaptıkları “Akıllı Telefonların Uygulama İzinleri Üzerine Bir Farkındalık Çalışması’nda” öğrencilerin akıllı telefonlarını her zaman ve sık sık kullandıkları ve istenilen uygulama izinlerinin farkında oldukları ama bu izinlerin içeriklerini okumadıkları sonucuna ulaşılmıştır. Aynı çalışmada indirilen mobil uygulamalarını kullanabilmek için en çok kabul edilen izinler arasında; kamera, konum bilgisi, mikrofon ve galeri bulunmaktadır. Kabul edilmeyen uygulama izinleri içerisinde ise, rehber, mesaj, telefon ve galeri bulunmaktadır. Bireylere istenilen uygulama izinlerini neden kabul ettikleri sorulduğunda, ankete katılanların \%88,1'i indirdikleri uygulamaları sorunsuz (eksiksiz) kullanabilmek için kabul ettiklerini belirtmişlerdir.

Sonuç olarak Sosyal bilgiler öğretmenlerinin GPS ve CBS sistemleri hakkında yüzeysel bir bilgiye sahip oldukları görülmektedir. Bu yetersizliğin önemli nedenlerinden biri olarak hizmet öncesi dönem olarak ifade edilen lisans eğitiminde sosyal bilgiler öğretmen adaylarına teknoloji temelli bir Coğrafya eğitiminin verilmemiş olması gösterilebilir. Ayrıca Milli Eğitim Bakanlığına bağlı okullarda GPS ve CBS sistemleri ile ilgili nitelikli hizmet içi eğitim seminerlerinin verilmiyor olması da diğer bir neden olarak ifade edilebilir. Lisans seviyesinde programa eklenecek teknoloji temelli bir Coğrafya dersi ile ya da GPS ve CBS sistemlerinin kullanımıyla ilgili Milli Eğitim Bakanlığg'na (MEB) bağlı okullarda görev yapan öğretmenlere verilecek nitelikli hizmet için eğitim seminerleriyle öğretmen yeterlilikleri istenilen düzeye çıkarılabilir. Ayrıca alanyazın incelendiğinde konuyla ilgili sosyal bilgiler öğretmenlerine yönelik çalışmaların yetersiz olduğu da tespit edilmiştir. Bu çalışmanın hem alanyazınla ilgili bir eksikliği dolduracağı hem de ilgili araştırmacılara konunun farklı boyutlarını dikkate alan çalışmalar yapmalarına rehberlik edeceği düşünülmektedir.

\section{Makalenin Bilimdeki Yeri}

Sosyal Bilgiler Anabilim Dalı

\section{Makalenin Bilimdeki Özgünlüğü}

Gelişen teknoloji ile birlikte insanların çevrelerine adapte olabilmeleri için ihtiyaç duyacakları teknolojik bilgi ve yeterlilikler de artmaktadır. Bu yeterliliklerden biri de Küresel Konumlandırma Sistemlerini kullanabilme becerisidir. Bu yeterliliğin eğitim kurumlarında öğretmenler tarafından aktarılması oldukça önem araz etmektedir. Öğretmenlerin teknolojinin birçok alanında meydana gelen değişim ve yenilikleri yakından takip ederek, bunları öğrencileriyle paylaşmaları küresel vatandaş yetiştirme amacı güden eğitim sistemlerinin en nihai hedefidir. Bu genel hedefi gerçekleştirme konusunda önemli görevler üstlenen branşların 
başında sosyal bilgiler öğretmenliği gelmektedir. En temel amacı etkili ve nitelikli vatandaş yetiştirme olan sosyal bilgiler dersinin uygulayıcıları konumunda olan öğretmenlerin, bilgisayar destekli bilgi teknolojilerini kullanabilmeleri ve bu beceriyi etkili kullanma konusunda öğrencilerine rol model olmaları sosyal bilgiler öğretim programının hedeflerine ulaşması bakımından oldukça önemlidir. Alanyazın incelendiğinde de Sosyal Bilgiler Öğretmenlerinin konumlandırma sistemleri ile alakalı görüşlerini veya yeterlilikleri ortaya koyan çalışmalar yok denecek kadar azdır. Bu çalışmanın da alanyazındaki eksikliği doldurması ve konuyla ilgili gelecekte yapılacak çalışmalara zemin oluşturması beklenmektedir.

\section{Kaynaklar}

Artvinli, E.(2009). Coğrafya öğretmenlerinin coğrafi bilgi sistemleri (CBS)’ne ilişkin yaklaşımları. Ballkesir Üniversitesi Sosyal Bilimler Enstitüsü Dergisi, 12 (22). 40-57

Aytaçlı, B. (2012). Durum çalışmasına ayrıntılı bir bakış. Adnan Menderes Üniversitesi Eğitim Fakültesi Eğitim Bilimleri Dergisi, 3 (1), 1-9

Balcı, A. ve Şahin, F., T. (2018). Öğretmen-Aile İletişiminde WhatsApp Uygulamasının Kullanımı. GEFAD / GUJGEF 38(2). http://www.gefad.gazi.edu.tr/download/article-file/515837

Büyüköztürk, Ş., Çakmak, E., K., Akgün, Ö., E., Karadeniz, Ş. ve Demirel, F. (2016). Bilimsel araştırma yöntemleri. Ankara: Pegem Akademi

Christopher J. and Kaplan E.D. (2006). Understanding GPS: Principles and Applications. Artech House Publishing, P.9, 563.Boston, London.

Demirci, A., Karaburun, A., Ünlü, M. ve Özey, R. (2013). Okullarda cbs tabanl projeler: uygulama ve değerlendirme. Coğrafyacılar Derneği Yıllık Kongresi Bildiriler Kitabı 19-21 Haziran 2013, Fatih Üniversitesi, İstanbul.

Demirci, A. (2008). Evaluating the implementation and effectiveness of GIS based application in secondary school geography lessons. American Journal of Applied Sciences, 5(3), 169 European GNSS Agency. (2017). GNSS Market Report - Issue 5. P.29. Luxembourg, European Union.

Karlı, İ., Doğru, S. ve Doğru ve Doğru, Y., B. (2018). Akıllı Telefonların Uygulama İzinleri Üzerine Bir Farkındalık Çalışması. Online Academic Journal of Information Technology, 9(30). (Erişim 
YYÜ Eğitim Fakültesi Dergisi (YYU Journal of Education Faculty), 2019; 16(1):1492-1514, http://efdergi.yyu.edu.tr

http://dx.doi.org/10.23891/efdyyu.2019.169

Araştırma Makalesi

ISSN: 1305-020

tarihi:25.01.2019)http://akademikpersonel.kocaeli.edu.tr/yusuf.dogru/diger/yusuf.dogru17.10. 2018_10.52.44diger.pdf

Kulkarni, M.,N. (...).The Global Positıoning System And Its Applicatıons. Department of Civil Engineering Indian Institute of Technology, Bombay. Powai, MUMBAI - 400076.

Milson, A. J, Kerski, J. J., \& Demirci, A. (2012). The world at their fingertips: A new age for spatial thinking. A. J. Milson, A. Demirci, \& J. J. Kerski (Ed.), International Perspectives on Teaching and Learning with GIS in Secondary Schools.New York: Springer.NCSR (2007). Geographıc informatıon systems. (Erişim tarihi: 25.01.2019) https://learnforests.org/sites/default/files/GeographicInformationSystems.pdf

Prasad R. and Ruggieri M. (2005). Applied satellite navigation using gps, gallleo, and augmentation systems, P.38-40, Artech House Publishing, Boston, London.

Rhee, Y. (2004). The EPO chain in relationships management: a case study of a government organization. Unpublished doctoral dissertation, University of Maryland, College Park

Statista (2019). Number of monthly active WhatsApp users worldwide from April 2013 to "December 2017. (Erişim tarihi: 25.01.2019) https://www.statista.com/statistics/260819/number-ofmonthly-active-whatsapp-users/

Taylor, G. And Blewwit, G. (2006). Intelligent Positioning: GIS - GPS Unification. John Wiley \& Sons Ltd., P.26 England.

Tecim, V. (2008). Coğrafi bilgi sistemleri, harita tabanlı bilgi yönetimi. Ankara: Renk Form Ofset Maybaac1l1k

Tuna, F. (2015). Kartoğrafya: Haritacılık Bilimine Giriş.Ankara: Pegem Akademi Yayınları

Turoğlu, H. (2000). Coğrafi Bilgi Sistemlerinin Temel Esasları.İstanbul: Acar Matbaacılık

Yıldırım, A. ve Şimşek H. (2011). Sosyal bilimlerde nitel araştırma yöntemleri. Ankara: Seçkin Yayınc1lık 


\section{EXTENDED ABSTRACT}

\section{Introduction}

We live in an age where technology affects our lives deeply. These developments in global technology have made the world's most remote settlement point accessible in a short time. The ease of accessibility, which can be considered as a reason of the concept of space, has minimized the time and space mismatch and changed the approach to the geographic location. The most important developments of mass media provides important developments and facilities in ensuring the integrity and harmony of time and space. Global Positioning System, known as GPS (Global Positioning System), is the basic technology that enables the use of mass media or networks such as wireless phones (mobile phones) and the Internet. The Global Positioning System (GPS) is a satellite-based navigation and surveying system for determination of precise position and time, using radio signals from the satellites, in realtime or in post-processing mode. GPS is being used all over the world for numerous navigational and positioning applications, including navigation on land, in air and on sea, determining the precise coordinates of important geographical features as an essential input to mapping and Geographical Information System (GIS), along with its use for precise cadastral surveys, vehicle guidance in cities and on highways using GPS-GIS integrated systems, earthquake and landslide monitoring, etc. In India also, GPS is being used for numerous applications in diverse fields like aircraft and ship navigation, surveying, geodetic control networks, crustal deformation studies, cadastral surveys, creation of GIS databases, time service, etc., by various organisations (Kulkarni, ?). Global Positioning System (GPS) provides ease of use in Geographic Information Systems (GIS) applications. GIS can be defined as "any sequence of interrelated functions that achieves the input, storage, processing, and subsequent generation of spatial data.” GIS gives a "high tech feel” to geographic information, maps are fascinatingespecially in computers, and there is increasing interest in geography and geographic 
education. And GIS is a uniquely important tool in understanding and managing the environment (NCSR, 2007). Since many countries have recognized the potential of GIS in terms of education and training, these practices have become widespread (Demirci et al., 2013). Teachers have an important role in following computer technologies and transferring their learning to the classroom. The aim of this research is to reveal the views of social studies teachers about global positioning system (GPS) and geographic information systems (GIS).

\section{The aim of the research}

The aim of this research is to reveal the views of social studies teachers about global positioning system (GPS) and geographic information systems (GIS).

\section{The method}

This study is a case study which is one of qualitative research design. Case study is a research methodology, typically seen in social and life sciences. Mitchell (1983) defined a case study as a "detailed examination of an event (or series of related events) which the analyst believes exhibits (or exhibit) the operation of some identified general theoretical principles” (p. 192). Yin (1994) defined a case study as "an empirical inquiry that investigates a contemporary phenomenon within its real-life context, especially when the boundaries between phenomenon and context are not clearly evident...[and] relies on multiple sources of evidence” (p. 13). As Yin said, one should use a case study strategy because he or she deliberately wants to study contextual conditions (As cited in Rhee, 2004). In this study we deliberately reveal the views of social studies teachers about global positioning system (GPS) and geographic information systems (GIS).

\section{Results and discussion}

When the first findings obtained from the interviews with the social studies teachers are examined for this purpose; it is seen that teachers define the GPS system, which is known as GIS (Geographic Information Systems) technology, as a positioning system or as a system 
which locates by satellite. This result reveals that social studies teachers do not have enough knowledge about geographic information systems. When the literature is reviewed, it is seen that there is no study on what other teachers, except for geography teachers, know about Geographic Information Systems (GIS) or Global Positioning Systems (GPS). The GIS using in our country has a 10 years history. However, as it can be easily seen when compared with different countries, this usage is not at the desired level considering all the geography teachers within the country (Demirci, Karaburun, Ünlü ve Özey, 2013). No doubt in the emergence of this situation; different factors arising from school and education system, teachers, infrastructure and curriculums (Demirci 2008). When the second finding is examined, it is seen that teachers stated that GPS is mostly used in transportation sector and for determining location. It is seen that the teacher don't have enough information about the use of GIS system, which has many different usage functions. When the third finding is examined, it is seen that teachers know the applications in smart phones or tablets and they use this system only to send the address to the opposite side. It is understood from the teachers answer that they do not have enough information about positioning services which have many usage areas such as showing places, the coordinates of the person's location, getting directions, sharing the location, the nearest hospital, pharmacy, school, oil station and so on. When the fourth finding is examined, it can be concluded that teachers know how to send locations via WhatSApp (by clicking the add sign) and according to them this system provides much convenience in address finding, transportation and communication. According to the latest statistics available, as of October 2018, this puts WhatsApp in the number one spot in a ranking of global messenger apps, with some 200 million more users than Facebook Messenger (Statista, 2019). When the fifth finding is examined, teacher stated that they solved the problem of address in a city where they did not know by devices such as GPS or navigation devices. The last finding is that when teachers download an app to their smartphone or tablet, they usually say no for security purposes to the 
YYÜ Eğitim Fakültesi Dergisi (YYU Journal of Education Faculty), 2019; 16(1):1492-1514, http://efdergi.yyu.edu.tr

question of "Share your location or access your location? When installing applications to smart devices, the desired permissions may sometimes cause personal information to be received by others. 